16 Persson L, Hardemark HG, Gustafsson G, Rundstrom G, Mendel-Hartvig I, Esscher T, et al. S100 protein and neuron-specific enolase in cerebrospinal fluid and serum: marker of cell damage in human central nervous pinal fluid and serum: marker

17 Ingebrichtsen T, Romner B, Kongstad P, Langbakk B. Increased serum levels of protein S100 after minor head injury: a biochemical serum marker with prognostic value? J Neurol Neurosurg Psychiatry 1995;59:103-4.

18 Usui A, Kato K, Abe T, Murase M, Tanaka M, Takeuchi E. S100a0 protein in blood and urine during open heart surgery. Clin Chem 1989:35:1942-4

19 Weber T, Poser S, Zerr I, Räcker S, Behring B, Bogumil T, et al. Epidemiology and early diagnosis of human prion diseases. J Neurol 1995; 242:257

20 Will RG. Epidemiology of Creutzfeldt-Jakob disease. Br Med Bull 1993;49:960-70.

21 Windl O, Dempster M, Estibeiro JP, Lathe R, de Silva R, Esmonde T, et al. Genetic basis of Creutzfeldt-Jakob disease in the United Kingdom: a systematic analysis of predisposing mutations and allelic variation in the PRNP gene. Hum Genet 1996;98:259-64.
22 Vollset SE. Confidence intervals for a binominal proportion. Stat Med 1993;12:809-24.

23 Youden WJ. Index rating for diagnostic tests. Cancer 1950;3:32-5.

$24 \mathrm{Metz}$ CE. Basic principles of ROC analysis. Semin Nucl Med 1978;8:283-98.

25 Lee KH, Harrington MG. Premortem diagnosis of Creutzfeldt-Jakob disease by cerebrospinal fluid diagnosis. Lancet 1996;348:887.

26 Moussavian M, Potolicchio S, Jones R. The 14-3-3 brain protein and transmissible spongiform encephalopathy. N Engl J Med 1997;336:873-4

27 Astudillo R, Van der Linden J, Radegran K, Hansson L-O, Aberg B. Elevated serum levels of S100 after deep hypothermic arrest correlate with duration of circulatory arrest. Eur J Cardiothorac Surg 1996;10:110713 .

28 Jensen R, Marshak DR, Anderson C, Lukas TJ, Watterson DM. Characterization of human brain $\mathrm{S} 100$ protein fraction: amino acid sequence of S100 beta. J Neurochem 1985;45:700-5.

(Accepted 28 October 1997)

\title{
Slater revisited: 6 year follow up study of patients with medically unexplained motor symptoms
}

Helen L Crimlisk, Kailash Bhatia, Helen Cope, Anthony David, C David Marsden, Maria A Ron

See editorial by

O'Brien

Institute of

Neurology, London

WC1N 3BG

Helen L Crimlisk,

research fellow

Kailash Bhatia,

senior lecturer

C David Marsden,

professor of neurology

Maria A Ron,

professor of

neuropsychiatry

Institute of

Psychiatry, London

SE5 8AF

Helen Cope,

senior lecturer

Anthony David,

professor of cognitive

neuropsychiatry

Correspondence to:

Professor Ron

M.RON@ion.

ucl.ac.uk

BMJ 1998;316:582-6

\begin{abstract}
Objective: To investigate psychiatric and neurological morbidity, diagnostic stability, and indicators of prognosis in patients previously identified as having medically unexplained motor symptoms.

Design: Follow up study.

Setting: National Hospital for Neurology and Neurosurgery, London-a secondary and tertiary referral hospital for neurological disorders.

Subjects: 73 patients with medically unexplained motor symptoms admitted consecutively in 1989-91. $35(48 \%)$ patients had absence of motor function (for example, hemiplegia) and 38 (52\%) had abnormal motor activity (for example, tremor, dystonia, or ataxia).
\end{abstract}

Main outcome measures: Neurological clinical diagnosis at face to face reassessment by a neurologist and a psychiatric diagnosis after a standardised assessment interview-the schedule for affective disorders and schizophrenia-conducted by a psychiatrist.

Results: Good follow up data were available for 64 subjects $(88 \%)$. Only three subjects had new organic neurological disorders at follow up that fully or partly explained their previous symptoms. 44/59 (75\%) subjects had had psychiatric disorders; in 33 (75\%) patients, the psychiatric diagnosis coincided with their unexplained motor symptoms. 31/59 (45\%) patients had a personality disorder. Three subjects had developed new psychiatric illnesses at follow up, but in only one did the diagnosis account for the previous motor symptoms. Resolution of physical symptoms was associated with short length of symptoms, comorbid psychiatric disorder, and a change in marital status during follow up.

Conclusions: Unlike Slater's study of 1965, a low incidence of physical or psychiatric diagnoses which explained these patients' symptoms or disability was found. However, a high level of psychiatric comorbidity existed.

\section{Introduction}

In 1965 Elliott Slater published a highly influential study in the British Medical Journal that described a 10 year follow up study of patients admitted to the National Hospital for Nervous Diseases with a diagnosis of "hysteria." $2 \mathrm{He}$ found that over half of the patients developed clear cut neurological or psychiatric conditions during follow up. Since the 1960s several studies investigating the subsequent incidence of neurological disorder in patients with a diagnosis of "hysteria" or "conversion disorder" have been published, and rates of up to $25 \%$ have been reported. ${ }^{3-8}$ The proportion of patients whose symptoms are not adequately explained in physical terms and who are being cared for by British neurologists ranges from $20 \%$ to $40 \%{ }^{9}{ }^{10}$ Both neurologists and psychiatrists are therefore cautious about making a firm diagnosis in this group of patients. ${ }^{11}$

Thirty years after Slater's work, we carried out a follow up study on a similar population of patients. We attempted to avoid some of the methodological problems of previous studies. Our subjects were a consecutive series with unexplained motor symptoms, admitted between 1989 and 1991 to the National Hospital for Neurology and Neurosurgery, London (formerly the National Hospital for Nervous Diseases). All the patients had been thoroughly investigated with modern diagnostic techniques and all were eligible for inclusion, not only those who had been referred to a psychiatrist. Outcome was assessed on the basis of face to face neurological and psychiatric examination and scrutiny of all available medical records. Standardised instruments were used to ascertain the presence of psychiatric disorder.

\section{Methods}

Hospital discharge summaries of all patients aged 18-70 years who had been admitted between 1989 and 1991 were reviewed. We identified 73 consecutive sub- 
jects who had presented with motor symptoms that were medically unexplained despite full investigation. The index motor symptom at presentation was categorised as either absence of motor function-for example, hemiplegia or paraplegia-or presence of abnormal motor activity, such as tremor, dystonia, or ataxia. Although motor disorders could be continuous or intermittent, we excluded those patients with apparent unconsciousness (that is, pseudoepileptic seizures) or whose impaired motor function was caused predominantly by pain or fatigue. The presence of a coexistent neurological disorder that did not account for the current symptom was not an exclusion criterion.

General practitioners, neurologists, and psychiatrists were asked if they objected to us contacting their patients. Patients who agreed to participate in the study were seen at the hospital or visited at home. Ethical approval was obtained for the study.

\section{Follow up assessment}

At follow up during 1996, subjects underwent a semistructured interview designed to assess the evolution of the index symptom, the occurrence of other somatic or psychological symptoms, the subjects' utilisation of medical and psychiatric services, and details of any state financial benefits received. The schedule for affective disorders and schizophrenia was completed for each subject, and this was supplemented by all available hospital and general practitioner records. ${ }^{12}$ Current and lifetime diagnoses according to the 10th revision of the international classification of diseases were obtained. ${ }^{13}$ Subjects were reassessed physically by a neurologist.

\section{"Organicity" rating}

To validate the selection of subjects, initial ratings of "organicity" were undertaken by a psychiatrist and a neurologist blinded to the outcome. Ratings were based on the medical history taken at the index admission to hospital, the clinical findings at the time of admission, examination of the subjects' physical and mental state, results of investigations, and progress while in hospital. With a scale of $0-3$, an organicity rating of 0 was given if the index symptom had no organic basis, and a rating of 3 was given if the index symptom was fully explained by organic factors. The mean of the ratings given by the psychiatrist and neurologist formed the initial organicity rating. A final organicity rating was undertaken by a neurologist and psychiatrist at follow up, based on assessment at that time and including further information gathered to date.

\section{Statistical analysis}

Factors associated with good outcome were determined by multiple backward stepwise regression analysis using SPSS software. Subjects with a subsequent new diagnosis and those for whom follow up information was inadequate were excluded from the analysis.

\section{Results}

Good follow up data were available for 64 of the 73 subjects $(88 \%)$ ). Of these, 55 underwent full interview and examination, four cooperated fully with access to
Table 1 Symptoms in 63 patients with additional unexplained neurological symptoms*

\begin{tabular}{lc} 
Additional unexplained symptoms & No (\%) of patients \\
\hline Paraesthesia & $47(65)$ \\
\hline Bladder or bowel symptoms & $18(25)$ \\
\hline Pseudoepileptic seizures & $17(23)$ \\
\hline Memory impairment & $15(20)$ \\
\hline Visual disturbance & $10(14)$ \\
\hline Dysphonia or dysarthria & $4(5)$ \\
\hline Dysphasia & $3(4)$ \\
\hline Disturbed hearing & $1(1)$ \\
\hline
\end{tabular}

*31 patients had >1 additional unexplained neurological symptom.

records and a telephone interview but declined to be examined, and five had died (full medical notes and cause of death were obtained). Follow up data were incomplete in the remaining nine subjects $(12 \%)$. One patient could not be traced (she had given false personal details), and general practitioners asked us not to contact five subjects, although their notes and correspondence were made available to us. In a further three cases the subjects declined to cooperate and refused access to their notes. Because the results include all patients on whom information was available, denominators may differ.

\section{Characteristics of subjects}

The mean (SD) age of the $38(52 \%)$ men was not significantly different from that of the $35(48 \%)$ women (38 (13.2) v 35 (12.4) years). Seventy subjects (96\%) were white, and 21 (29\%) were of social class I or II. There were no differences between the nine subjects who did not respond and the remainder in terms of age, sex, social class, or marital status. At the time of the index admission, only 8 (11\%) subjects were still working, but $56(77 \%)$ had been in paid employment before the onset of their symptoms. Twenty nine subjects $(40 \%)$ were on sick leave and $22(30 \%)$ had already retired on the grounds of ill health. Sixteen (22\%) subjects had worked in medical or paramedical areas.

\section{Neurological symptoms and signs}

In the initial organicity ratings undertaken to validate the selection of subjects, 67 subjects $(92 \%)$ had a rating less than 1 and six subjects (8\%) had ratings between 1 and 2. No subject had a rating of 2 or more. Thirty five subjects $(48 \%)$ had absence of motor function (weakness) as the index symptom, and $38(52 \%)$ had abnormal motor activity-tremor (12 subjects (16\%)), dystonia (13 subjects (18\%)), and ataxia (13 subjects $(18 \%))$. The duration of index symptoms at admission to hospital ranged from less than 1 month to 140 months (median 18 (26.6) months). Index symptoms were predominantly right sided in 20 subjects $(27 \%)$, left sided in 21 subjects (29\%), and bilateral in the remainder. Most subjects also had other unexplained neurological symptoms or signs (table 1). Subjects with weakness were more likely to be male than female (23 $(32 \%)$ v $12(16 \%) ; \mathrm{P}=0.02, \chi^{2}$ test); of these 35,20 $(57 \%)$ had unilateral weakness (hemiplegia), 9 (26\%) had weakness in both legs (paraplegia), and 6 (17\%) had weakness in both arms and legs. One of the 10 subjects with left hemiplegia and three of the 10 subjects with right hemiplegia were left handed. 
Table 2 Range of disorders in the 31 subjects with history of organic neurological disorder

\begin{tabular}{lc} 
& No of patients \\
\hline Organic brain disease: & 15 \\
\hline Migraine & 6 \\
\hline Epilepsy & 2 \\
\hline Mild mental handicap & 2 \\
\hline Arrested hydrocephalus & 1 \\
\hline Cerebellar haemangioma & 1 \\
\hline Cerebrovascular accident & 1 \\
\hline Arnold-Chiari malformation & 1 \\
\hline Parkinson's disease & 1 \\
\hline Neurological disorder (no brain disease): & 16 \\
\hline Previous disc surgery & 9 \\
\hline Peripheral nerve palsy & 3 \\
\hline Diabetic neuropathy & 1 \\
\hline Myasthenia gravis & 1 \\
\hline Steroid myopathy & 1 \\
\hline Urinary dyssynergia & 1 \\
\hline
\end{tabular}

Thirty one subjects (42\%) had a history of organic neurological disorder, although only 15 of these (21\%) had disorders affecting the brain (table 2). The current unexplained symptoms were similar to those related to the previous neurological disorder in only 11 subjects (15\%). In addition, 32 subjects $(44 \%)$ had had previous episodes of unexplained neurological symptoms; in 26 $(81 \%)$ these symptoms were dissimilar to the index symptom. Thirty four subjects $(47 \%)$ had had nonneurological medically unexplained symptoms, and 14 $(20 \%)$ fulfilled the ICD-10 criteria for somatisation disorder.

\section{Psychiatric disorder}

Of the 59 subjects for whom this information was available, $44(75 \%)$ had had a psychiatric disorder as determined by the scale of affective disorder and schizophrenia (SADS). The most common diagnoses were depressive disorder (24 subjects (41\%)) and anxiety or phobic disorders (9 subjects (15\%)). Psychotic symptoms were uncommon; only four subjects $(7 \%)$ had these. No significant differences in the prevalence of psychiatric diagnoses existed in relation to age, sex, or social class. The psychiatric disorder had coexisted with the unexplained motor symptoms in 33 subjects (56\%). Of these 59 subjects, 31 (53\%) fulfilled criteria for a personality disorder. The most common subtypes were "dependent" (7 subjects), "emotionally unstable" (7 subjects), and "anxious" (6 subjects). Histrionic personality disorder was present in only four subjects $(6 \%)$. Six subjects $(8 \%)$ had a concurrent history of substance misuse (mostly associated with alcohol).

\section{Neurological diagnoses at follow up}

The organicity rating was the same at follow up in $47 / 69$ subjects $(68 \%)$ and had fallen in 17 (25\%), suggesting a greater degree of certainty at that time. The rating had increased at follow up in the remaining five subjects (7\%). In two of the five, the organic component was still insufficient to explain the symptom; in the other three, an organic neurological diagnosis was considered retrospectively to have explained the presenting symptom. The first of the three, a 25 year old woman who had presented with falls and abnormal gait and was of low intelligence, was diagnosed as having genetically confirmed myotonic dystrophy 4 years later. At follow up, the clinical picture had worsened and she had considerable difficulty with walking, swallowing, and breathing. A 49 year old man, first seen with a gait disorder, had been diagnosed as having spinocerebellar degeneration 3 years after his admission to hospital. Communication was difficult because English was not his first language. At follow up his gait, posture, speech, and swallowing had deteriorated appreciably. The diagnosis of a gait disorder in a 68 year old man was changed to one of paroxysmal hemidystonia at follow up.

Five subjects (7\%) had died by the time of follow up. The causes of death are detailed in table 3 . In no case was there evidence of a new diagnosis related to the original symptom.

\section{Psychiatric diagnoses at follow up}

At follow up, 23/64 subjects had a current psychiatric diagnosis. This was more often the case in those with abnormal motor activity rather than weakness $\left(\mathrm{P}=0.04, \chi^{2}\right.$ test). Most current disorders represented either a continuation or a relapse of a previous psychiatric disorder. However, three subjects had developed a new psychiatric disorder. A 48 year old woman with a head tremor now had florid psychotic symptoms and the head tremor was considered retrospectively to be part of a schizophrenic syndrome. A 49 year old man with unsteady gait and a 40 year old man with hemiplegia had developed major depressive disorders. The motor disorder had resolved only in the third subject.

\section{Outcome}

When the 64 subjects whose organicity rating had not increased at follow up were considered, only 21 (33\%) were in full time employment; $30(47 \%)$ were now retired on the grounds of ill health and two (3\%) remained on sick pay from their job. The index symptom had completely resolved in 18 of these subjects

Table 3 Details of five patients who died before follow up

\begin{tabular}{|c|c|c|c|c|c|c|}
\hline Age & Sex & $\begin{array}{l}\text { Non-organic index } \\
\text { symptom }\end{array}$ & Psychiatric diagnoses & Cause of death & Other somatisation & $\begin{array}{l}\text { State of index } \\
\text { symptom at death }\end{array}$ \\
\hline 22 & $\mathrm{~F}$ & Quadriplegia & $\begin{array}{l}\text { Dependent personality } \\
\text { disorder, depressive disorder }\end{array}$ & $\begin{array}{l}\text { Pneumonia secondary to } \\
\text { immobility }\end{array}$ & $\begin{array}{l}\text { Abdominal pain, joint pains, } \\
\text { unexplained urinary problems, } \\
\text { pseudoseizures }\end{array}$ & Worse \\
\hline 51 & M & Right hemiplegia & $\begin{array}{l}\text { Somatisation disorder, } \\
\text { cognitive impairment, anxiety } \\
\text { and panic attacks }\end{array}$ & Congestive cardiac failure & $\begin{array}{l}\text { Abdominal pain, headaches, } \\
\text { backache, non-cardiac chest pain, } \\
\text { hyperventilation }\end{array}$ & Unchanged \\
\hline 62 & M & Unsteady gait & None & Myeloproliferative disorder & None & Unchanged \\
\hline
\end{tabular}


Table 4 Factors predicting outcome in 64 subjects whose organicity rating was not increased at follow up

\begin{tabular}{|c|c|c|c|c|c|c|}
\hline Factors & $\begin{array}{c}\text { Symptom } \\
\text { better }(n=31)\end{array}$ & $\begin{array}{l}\text { Symptom not } \\
\text { better }(n=33)\end{array}$ & \multicolumn{2}{|c|}{$\begin{array}{l}\text { Logistic regression analysis } \\
\text { (unadjusted) }\end{array}$} & \multicolumn{2}{|c|}{$\begin{array}{l}\text { Logistic regression analysis } \\
\text { (adjusted) }\end{array}$} \\
\hline \multicolumn{7}{|l|}{ Demographic: } \\
\hline Female sex & 18 & 14 & 0.21 & 1.88 (0.69 to 2.72$)$ & 0.99 & $1.01(0.15$ to 6.60$)$ \\
\hline Social class $<3$ & 16 & 20 & 0.47 & 0.69 (0.14 to 3.52$)$ & 0.86 & $1.18(0.12$ to 8.41$)$ \\
\hline Duration of symptom $<1$ year & 27 & 16 & 0.013 & $0.24(0.08$ to 0.74$)$ & 0.018 & $0.11(0.02$ to 0.67$)$ \\
\hline Litigation pending at time of admission & 4 & 11 & 0.062 & 0.30 (0.08 to 1.05$)$ & 0.066 & $0.09(0.01$ to 1.18$)$ \\
\hline $\begin{array}{l}\text { Comorbid SADS-L psychiatric disorder at } \\
\text { time of motor symptoms }\end{array}$ & 22 & 11 & 0.0034 & 4.89 (1.70 to 14.13$)$ & 0.025 & 7.34 (1.29 to 42.28$)$ \\
\hline \multicolumn{7}{|l|}{ Previous illness: } \\
\hline Change in marital status since admission & 10 & 2 & 0.015 & 7.38 (1.48 to 36.86$)$ & 0.008 & 33.66 (2.52 to 444.61$)$ \\
\hline Family history of chronic illness & 14 & 18 & 0.45 & $0.69(0.25$ to 1.92$)$ & 0.43 & $0.53(0.11$ to 2.51$)$ \\
\hline
\end{tabular}

SADS-L=schedule for affective disorders and schizophrenia.

(28\%) and had improved in $13(20 \%)$. The presenting symptom was unchanged in nine subjects (14\%), while in $24(38 \%)$ it had worsened. For the purposes of multiple logistic regression analysis, these subjects were grouped into the 31 who had improved, and the 33 who had not improved. The factors entered in the analysis are shown in table 4 . Factors associated with a good outcome were: symptoms present for less than 1 year at admission to hospital $(\mathrm{P}=0.018)$, a psychiatric diagnosis indicated by the schedule for affective disorders and schizophrenia that coincided with the unexplained motor symptoms $(\mathrm{P}=0.025)$, and a change in marital status during the follow up period $(\mathrm{P}=0.0075)$. Receipt of financial benefits at the time of admission to hospital indicated a poor prognosis $(\mathrm{P}=0.03)$, as did pending litigation $(\mathrm{P}=0.066)$.

\section{Discussion}

The incidence of subsequent neurological disorder in our study-indicative of initial misdiagnosis-was low. There was also little evidence that symptoms reflected new presentations of an undiagnosed psychiatric disorder. Mitigating factors explain misdiagnosis. In one subject, the diagnosis may have been missed because paroxysmal dystonias have only recently been recognised as a neurological entity. ${ }^{14}$ In two others, communication problems may have played a part. It is impossible to assert that the symptoms of the other subjects will never be explained by neurological diagnoses, but after 6 years of follow up this is increasingly unlikely. The high diagnostic accuracy probably reflects improved diagnostic skills as well as better noninvasive investigative techniques.

The equal sex ratio in our cohort, different from the female preponderance of previous studies, remains unexplained. However, the high incidence of affective, anxiety, somatisation, and personality disorders is similar to that previously reported..$^{15-17}$ Although five subjects had died by the time of follow up, their deaths did not reflect missed neurological diagnoses. It is important to remember that conversion disorder does not protect patients from developing serious physical illness. The presence of somatisation in other systems may have lead to delay in the diagnosis of severe non-neurological illnesses in two subjects. In a further two subjects who died at a young age, death may have been related to the sequelae of underlying psychiatric disorder.

Few studies have looked at indicators of prognosis. Our results support previous work which found that a short duration of symptoms was associated with a good outcome. ${ }^{7819}$ Pending litigation-as is often suggested anecdotally-also emerged as an indicator of poor prognosis. Changed marital status (in either direction) seemed to predict a good outcome, presumably reflecting a favourable change in personal circumstances. The association between comorbid psychiatric disorder and good outcome underlines the importance of screening for affective and anxiety disorders in these patients. These disorders may make some people vulnerable to developing conversion symptoms, which if managed inappropriately may lead to enduring disability. The findings suggest that treatments may need to be targeted specifically. Treating depression and anxiety aggressively and exploring relevant personal circumstances may reduce disability in some patients, while for those with several physical symptoms and personality disorder, prevention of iatrogenic damage and cost effective management strategies aimed at damage limitation may be more appropriate.

This study has several limitations. Follow up studies are always subject to attrition, although we managed to obtain data on $88 \%$ of subjects. The setting for the study, a secondary and tertiary neurological teaching hospital, limits the generalisability of our findings. Although inclusion of subjects selected was validated, cases may have been overlooked in the initial selection and milder cases may be underrepresented as they were not perceived to require referral to a neurological centre. Referral bias may explain the high social class, older age, and chronicity of our cohort compared with other studies. ${ }^{6}{ }^{19}$ Similarly, the extent to which organic disorders were excluded by special investigation may not be typical of that in other centres. Another 
limitation is the lack of a comparison group. Hence, we were unable to calculate the relative risk of psychiatric disorder in patients with unexplained motor symptoms compared with patients with clear cut neurological syndromes. However, the main purpose of the study was to look at changes within this group and at associated psychological and physical morbidity.

In summary, the stability of the diagnosis in patients with medically unexplained motor symptoms who have been investigated thoroughly is high. Neurologists should be encouraged to make a positive diagnosis early to avoid uncertainty in the minds of the patients, and other health care professionals, thus reducing the risks and costs of further unnecessary investigations. The opportunity to seek psychiatric disorder and treat it appropriately should not be missed.

Contributors: HLC interviewed patients and examined them psychiatrically, collected and analysed data, and wrote the various versions of the manuscript. $\mathrm{KB}$ examined the patients neurologically and was involved in the writing of the manuscript. HC and MAR were blind raters of patient documentation. AD, HC, CDM, and MAR had the original idea for the study, discussed core findings, and participated in the writing of the paper. MAR is the guarantor of the paper.

Funding: Joint Research Advisory Committee at the National Hospital for Neurology and Neurosurgery.

Conflict of interest: None.

1 Slater E. Diagnosis of hysteria. BMJ 1965;1:1395-9.

2 Slater E, Glithero E. A follow up of patients diagnosed as suffering from "hysteria." J Psychosom Res 1965;9:9-13.

3 Watson CG, Buranen C. The frequency and identification of false positive conversion reactions. J Nerv Ment Dis 1979;167:243-7.

4 Gatfield PD, Guze SBG. Prognosis and differential diagnosis of conversion reactions. Dis Nerv System 1962:23:623-31.

5 Raskin M, Talbott JA, Meyerson AT. Diagnosed conversion reactions: predicative value of psychiatric criteria. JAMA 1966;197:530-4.

6 Stephansson JG, Messina JA, Meyerowitz S. Hysterical neurosis, conversion type: clinical and epidemiological considerations. Acta Psychiatrica Scand 1976;53:119-38.

7 Couprie W, Widjdicks EFM, van Gijn Rooijmans J. Outcome in conversion disorder: a follow up study. J Neurol Neurosurg Psychiatry 1995;58:750-2.

8 Mace CJ, Trimble MR. Ten year prognosis of conversion disorder. $\mathrm{Br} J$ Psychiatry 1996;169:282-8.
Key messages

- Motor symptoms that remain unexplained medically despite thorough investigation are a common clinical problem, but the emergence of a subsequent organic explanation for these symptoms is rare

- The prevalence of coexistent affective and anxiety disorders is high and many patients also have a personality disorder

- Patients with a shorter duration of symptoms and coexistent anxiety or depression are likely to do better at follow up

- Reinvestigation of these patients is both expensive and potentially dangerous and should be avoided where no clear clinical indication exists

9 Mace CJ, Trimble MR. "Hysteria," "functional" or "psychogenic"? A survey of British neurologists' preferences. JR Soc Med 1991;84:471-5.

10 Ewald H, Rogne T, Ewald K, Fink P. Somatisation in patients newly admitted to a neurology department. Acta Psychiatrica Scand 1994;89:174-9.

11 Marsden CD. Hysteria-a neurologist's view. Psychol Med 1986;16:277-88.

12 Endicott J, Spitzer RL. A diagnostic interview: schedule and schizophrenia. Arch Gen Psychiatry 1978;35:837-66.

13 World Health Organisation. Clinical descriptions and diagnostic guidelines. The ICD-10 classification of mental and behavioural disorders. Geneva: World Health Organisation, 1992.

14 Demirkiran M, Jankovic J. Paroxysmal dyskinesias: clinical features and classification. Ann Neurol 1995;38:571-9.

15 Roy A. Hysteria.J Psychosom Res 1980;24:53-6.

16 Wilson Barnett J, Trimble MR. An investigation of hysteria using the illness behaviour questionnaire. Br J Psychiatry 1985;146:601-8.

17 Factor SA, Podskalny GD, Molho ES. Psychogenic movement disorders: frequency, clinical profile and characteristics. J Neurolog Neurosurg Psychiatry 1995;59:406-12.

18 Baker JE, Silver JR. Hysterical paraplegia. J Neurol Neurosurg Psychiatry 1987;50:375-82.

19 Lempert T, Dietrich M, Huppert D, Brandt T. Psychogenic disorders in neurology: frequency and clinical spectrum. Acta Neurol Scand 1990;82:335-40.

(Accepted 3 October 1997)

\section{A memorable patient}

\section{An ad hoc blood bank}

On a wet afternoon in 1953 a truck drew up at the foot of the steps of the hospital. Four Indian men carried a young boy inside. They operated a saw mill in the bush, they said. That morning the boy had fallen across the blade, which cut his leg off above the knee and then turned him around and went up his thigh and into the hip joint. He seemed to be dead so they covered him with a sack and carried on sawing.

Later, someone thought that they could see that he was breathing so they brought him to the hospital. The only sign of life was indeed a shallow respiration. Our blood bank was, so to speak, on the hoof. Donors were summoned, if they could be located, and were bled into the evacuated bottles supplied by the Canadian Red Cross. A time consuming business, which my partner and I at once instituted and, in the meantime, as both of us were $\mathrm{O}$ positive, we took a generous pint from each other and, after a quick major cross match, pumped the still warm blood into the patient.

Sister Superior came to say that the Indians had returned with the leg, still wearing a boot, and left it on the bottom step of the hospital. She also told us that, by chance, an official from the Ministry of Health, who was conducting a province wide survey of hospitals, had arrived. It seemed that he was utterly fascinated to learn what was going on in our quite small hospital, admirably run by the Sisters of Saint Anne. He had asked if it might be possible for him to observe our resuscitative efforts through a small window in the door of the operating theatre. I asked her to inquire if he knew his blood group. It was group O. Yes, I said, he could watch if he would agree to part with some of his blood. He said he would and I took a pint and a half.

I disarticulated what was left of the femur and the boy recovered. I met the ministry man over the years from time to time. He was always very friendly. I noted, however, that he never came back to our town.

Kenneth Macrae Leighton, retired professor of anaesthesia, Smithers, British Columbia, Canada

We welcome articles up to 600 words on topics such as $A$ memorable patient, a paper that changed my practice, My most unfortunate mistake, or any other piece conveying instruction, pathos, or humour. If possible the article should be supplied on a disk. Permission is needed from the patient or a relative if an identifiable patient is referred to. We also welcome contributions for "Endpieces," consisting of quotations of up to 80 words (but most are considerably shorter), from any source, ancient or modern, which have appealed to the reader. 